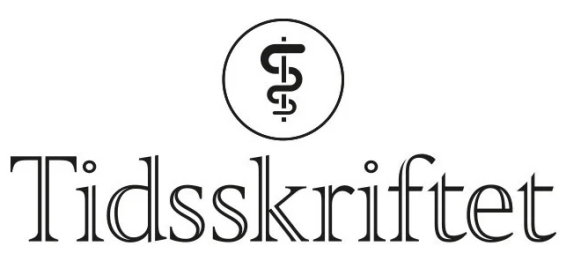

DEN NORSKE LEGEFORENING

\title{
Forbruk av opioider ved to kirurgiske sykehusavdelinger
}

KORT RAPPORT

\section{MARTHE A. PETTERSEN}

Det helsevitenskapelige fakultet

UiT - Norges arktiske universitet

Hun har bidratt med datainnsamling, databearbeiding, litteratursøk og skriving, og har godkjent det innsendte manuskriptet.

Marthe A. Pettersen er medisinstudent.

Forfatteren har fylt ut ICMJE-skjemaet og oppgir ingen interessekonflikter.

\section{TRUDE I. SMUKKESTAD}

Det helsevitenskapelige fakultet UiT - Norges arktiske universitet Hun har bidratt med datainnsamling, databearbeiding, litteratursøk og skriving, og har godkjent det innsendte manuskriptet.

Trude I. Smukkestad er medisinstudent.

Forfatteren har fylt ut ICMJE-skjemaet og oppgir ingen interessekonflikter.

\section{SIDSEL KRISTIANSEN}

Sykehusapotek Nord, Troms $\emptyset$

Hun har bidratt med datainnsamling, databearbeiding og skriving, og har godkjent det innsendte manuskriptet.

Sidsel Kristiansen er farmasøyt og medlem av legemiddelkomiteen ved Universitetssykehuset NordNorge.

Forfatteren har fylt ut ICMJE-skjemaet og oppgir ingen interessekonflikter.

\section{ASLAK JOHANSEN}

Smerteavdelingen

Operasjons- og intensivklinikken

Universitetssykehuset Nord-Norge

Han har bidratt med idé, utforming, litteratursøk og skriving, og har godkjent det innsendte manuskriptet.

Aslak Johansen er spesialist i anestesiologi og avdelingsoverlege. Han er styremedlem i Norsk forening for smertemedisin.

Forfatteren har fylt ut ICMJE-skjemaet og oppgir ingen interessekonflikter.

\section{LARS MARIUS YTREB $\varnothing$}

lars.marius.ytrebo@unn.no Operasjons- og intensivklinikken Universitetssykehuset Nord-Norge og 
Akuttmedisinsk og anestesiologisk forskningsgruppe

UiT - Norges arktiske universitet

Han har bidratt med idé, utforming, litteratursøk og skriving, og har godkjent det innsendte manuskriptet.

Lars Marius Ytrebø er spesialist i anestesiologi, overlege og professor.

Forfatteren har fylt ut ICMJE-skjemaet og oppgir ingen interessekonflikter.

Marthe A. Pettersen og Trude I. Smukkestad har bidratt i like stor grad til denne artikkelen.

\section{BAKGRUNN}

Formålet med undersøkelsen var å dokumentere forbruket av opioider ved to kirurgiske avdelinger ved Universitetssykehuset Nord-Norge Troms $\emptyset$ i perioden 2010-17.

MATERIALE OG METODE

Forbruket av opioider ved Gastrokirurgisk avdeling og Avdeling for hjerte-, lunge- og karkirurgi ble innhentet fra Sykehusapotek Nord. Alle opioider ble omregnet til orale morfinekvivalenter.

\section{RESULTATER}

Forbruket av morfin ved Gastrokirurgisk avdeling ble redusert fra 223835 orale morfinekvivalenter per år i perioden 2010-13 til 147641 i perioden 2014-17. Ved Avdeling for hjerte-, lunge- og karkirurgi ble forbruket av morfin per år redusert fra 28652 orale morfinekvivalenter i perioden 2010-13 til 22945 i perioden 2014-17. Forbruket av oksykodon ved Gastrokirurgisk avdeling økte fra 210643 orale morfinekvivalenter per år i perioden 2010-13 til 376322 i perioden 2014-17. Ved Avdeling for hjerte-, lunge- og karkirurgi økte forbruket av oksykodon fra 28922 orale morfinekvivalenter per år i perioden 2010-13 til 123 875 i perioden 2014-17. Ved Gastrokirurgisk avdeling var økningen tydeligst for oksykodon gitt intravenøst eller subkutant. Ved Avdeling for hjerte-, lunge- og karkirurgi var økningen størst for oksykodon administrert per os.

FORTOLKNING

Forbruket av opioider økte ved begge studieavdelingene, og oksykodon utgjorde størstedelen av økningen.

\section{HOVEDFUNN}

I perioden 2010-17 økte forbruket av opioider ved to kirurgiske avdelinger ved Universitetssykehuset Nord-Norge i Tromsø.

Endringen var i all hovedsak forårsaket av økt forbruk av oksykodon.

Opioider er effektive i behandling av akutt og postoperativ smerte (1 1 ). Opioider er vanedannende, og overforbruk er svært utbredt, de senere årene best dokumentert i USA og Canada $(\underline{2}, 3)$. Ved Universitetssykehuset Nord-Norge i Troms $\emptyset$ har morfin tradisjonelt vært førstevalgsopioid ved indikasjonen akutt og postoperativ smerte. Vår hypotese var at forbruket av opioider har endret seg over tid, og at oksykodon er i ferd med å erstatte morfin som førstevalg til pasienter med akutt og postoperativ smerte. Formålet med studien var å kartlegge forbruket av opioider ved to kirurgiske avdelinger ved Universitetssykehuset Nord-Norge i Tromsø i perioden 2010-17.

\section{Materiale og metode}


Gastrokirurgisk avdeling og Avdeling for hjerte-, lunge- og karkirurgi ble valgt som studieavdelinger fordi disse avdelingene ikke hadde gjennomgått organisasjonsmessige endringer som kunne ha påvirket Sykehusapotek Nords statistikk over utleverte legemidler. Tidsperioden 2010-17 ble valgt fordi Sykehusapotek Nord ikke hadde pålitelige data lenger tilbake i tid.

Salgstall for alle typer opioider til inneliggende pasienter i studieavdelingene ble innhentet fra sykehusapoteket. Dagkirurgiske pasienter er ikke medregnet, og heller ikke pasienter på postoperativ avdeling eller intensivavdeling. Forbruket av morfin og oksykodon ble omregnet til orale morfinekvivalenter med følgende omregningsfaktorer: $1 \mathrm{mg}$ morfin peroralt $=0,5 \mathrm{mg}$ oksykodon peroralt $=1$ oral morfinekvivalent, $\mathrm{og} 1 \mathrm{mg}$ morfin intraven $\varnothing \mathrm{st}=0,66 \mathrm{mg}$ oksykodon intraven $\varnothing \mathrm{st}=1 \mathrm{mg}$ ketobemidon intraven $\varnothing \mathrm{st}=10 \mathrm{mg}$ petidin intraven $\emptyset$ st $=3$ orale morfinekvivalenter. Omregningene er basert på konverteringstabellene for opioider til Smerteavdelingen og Regionalt kompetansesenter for lindrende behandling ved Universitetssykehuset Nord-Norge (4). Våre omregninger med hensyn til oksykodons relative potens i forhold til morfin er tidligere benyttet av andre (5, $\underline{6})$.

Studien ble registrert og godkjent som et kvalitetsprosjekt av Personvernombudet ved Universitetssykehuset Nord-Norge (registreringsnummer 2342).

\section{Resultater}

Antallet behandlingsdøgn i de to avdelingene endret seg lite i perioden 2010-17 (figur 1). Figur 2 viser det totale forbruket av morfin og oksykodon ved Gastrokirurgisk avdeling og Avdeling for hjerte-, lunge- og karkirurgi regnet om til orale morfinekvivalenter. Forbruket av morfin ved Gastrokirurgisk avdeling ble redusert fra gjennomsnittlig 223835 orale morfinekvivalenter per år i perioden 2010-13 til 147641 i perioden 2014-17. Ved Avdeling for hjerte-, lunge- og karkirurgi ble gjennomsnittlig forbruk av morfin redusert fra 28652 orale morfinekvivalenter per år i perioden 2010-13 til 22945 i perioden 2014-17.

Gastrokirurgisk avdeling $\square$ Avdeling for hjerte-, lunge- og karkirurgi

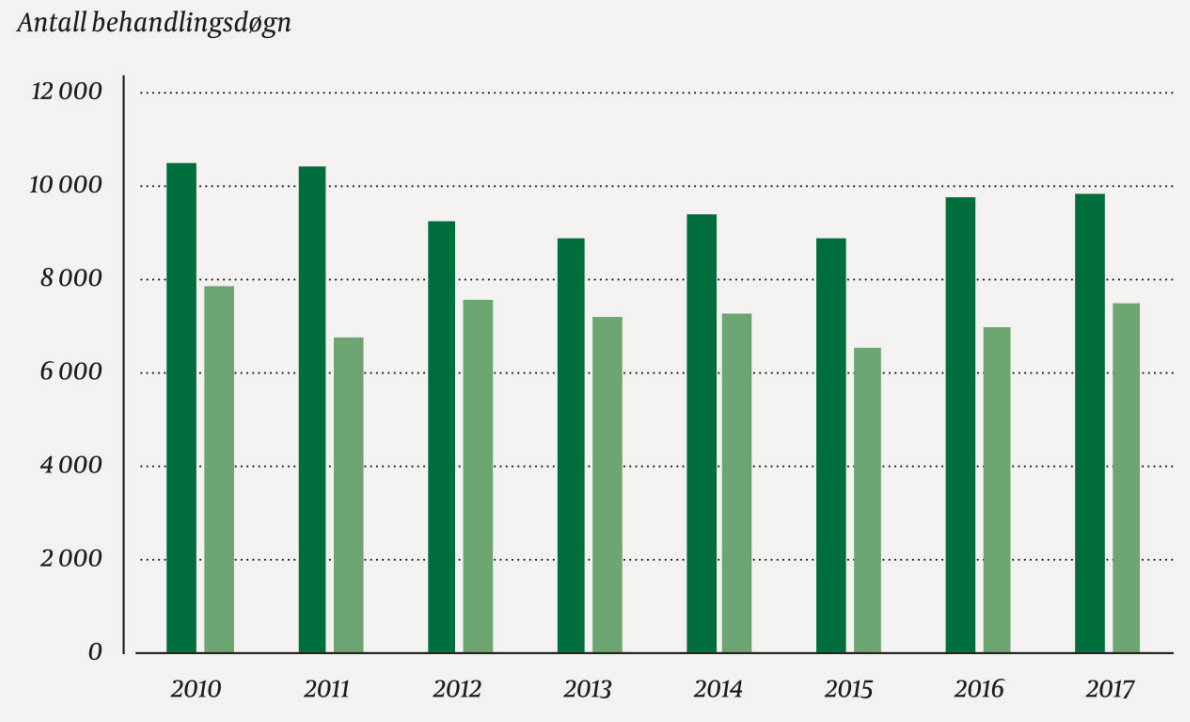

Figur 1 Antall behandlingsdøgn ved Gastrokirurgisk avdeling og Avdeling for hjerte-, lunge- og karkirurgi ved Universitetssykehuset Nord-Norge i perioden 2010-17. 
Morfin, Gastrokirurgisk avd. O Oksykodon, Gastrokirurgisk avd.

Morfin, Avd. for hjerte-, lunge- og karkirurgi Oksykodon, Avd.for hjerte-, lunge- og karkirurgi

Orale morfinekvivalenter

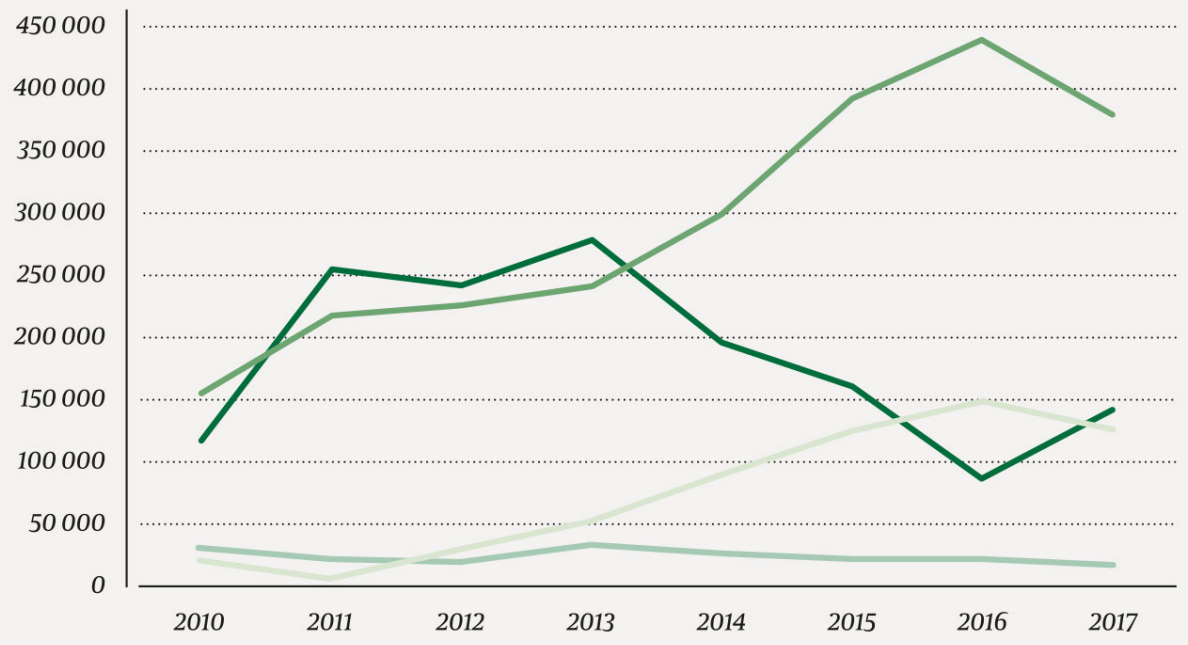

Figur 2 Forbruk av morfin og oksykodon omregnet til orale morfinekvivalenter ved Gastrokirurgisk avdeling og Avdeling for hjerte-, lunge- og karkirurgi ved Universitetssykehuset Nord-Norge i perioden 2010-17.

Det gjennomsnittlige forbruket av oksykodon ved Gastrokirurgisk avdeling økte fra 210643 orale morfinekvivalenter per år i perioden 2010-13 til 376322 i perioden 2014-17. Ved Avdeling for hjerte-, lunge- og karkirurgi økte forbruket av oksykodon fra gjennomsnittlig 28922 orale morfinekvivalenter per år i perioden 2010-13 til 123875 i perioden 2014-17.

Ved Gastrokirurgisk avdeling var endringen i forbruket tydeligst for legemidler gitt intravenøst eller subkutant, mens endringen ved Avdeling for hjerte-, lunge- og karkirurgi var mest markant for legemidler administrert per os.

Ketobemidon og petidin ble også forskrevet i studieavdelingene. I 2017 var forbruket av ketobemidon ved Gastrokirurgisk avdeling 225 orale morfinekvivalenter og ved Avdeling for hjerte-, lunge- og karkirurgi 3025 orale morfinekvivalenter. For petidin var tilsvarende tall 3 ooo og o.

\section{Diskusjon}

Mens totalforbruket av opioider har vist en beskjeden økning i Norge i perioden 1999-2013 (7.), har det de siste årene vært en tydelig økning i bruk av oksykodon i både Norge, Sverige og Danmark (모). I vår undersøkelse fant vi en klar økning i forbruk av oksykodon i begge studieavdelingene, mens forbruket av morfin ikke ble tilsvarende redusert.

Det finnes ingen fasit på hva som vil være riktig opioidforbruk i en kirurgisk avdeling. $\emptyset$ kningen i forbruket av opioider behøver derfor ikke være entydig negativ. Vi har ikke funnet overbevisende data som tilsier at det ene legemidlet er bedre egnet enn det andre (9.), og det er heller ikke nasjonal enighet om hva som bør være førstevalg for behandling av akutt og postoperativ smerte i sykehus. Temaet har tidligere vært debattert i Tidsskriftet $\mathrm{i}$ 2016 (10,11). Tilhengerne av oksykodon som førstevalgsopioid ved postoperativ og annen akutt sterk smerte argumenterte med forutsigbar absorpsjon peroralt (프), raskere anslagstid, få aktive metabolitter og mindre nyreavhengig eliminasjon. Motdebattantene mente det ikke var tilstrekkelig dokumentert at disse forskjellene var av klinisk betydning (11). 
I USA er det dokumentert at markedsføringen av oksykodon har vært offensiv og til dels misvisende (2) . Vi vet ikke i hvilken grad markedsføringen av oksykodon kan ha medvirket til praksisendringer i Norge (13).

Studien har begrensninger og svakheter. Vi kan ikke være sikre på at resultatene fra de to inkluderte avdelingene er representative for andre kirurgiske avdelinger ved Universitetssykehuset Nord-Norge. Vi har ingen opplysninger om faglige begrunnelser for at legene forskrev som de gjorde, og vi har heller ikke studert sammenhengen mellom opioidforbruk, diagnosekoder og type kirurgisk inngrep som ble utført. Opioidforbruket i denne studien omfatter ikke bare behandling av postoperativ smerte, men også pasienter med akutt smerte som ikke har gjennomgått kirurgi, pasienter innlagt med forverring av smertetilstander og pasienter med et etablert uhensiktsmessig forbruk av medikamenter og rusmidler.

Vi konkluderer med at forbruket av opioider økte ved begge studieavdelingene, og at oksykodon utgjorde størstedelen av denne økningen.

Artikkelen erfagfellevurdert.

\section{LITTERATUR}

1. Corbett AD, Henderson G, McKnight AT et al. 75 years of opioid research: the exciting but vain quest for the Holy Grail. Br J Pharmacol 2006; 147 (suppl 1): S153-62. [PubMed][CrossRef]

2. Helmerhorst GT, Teunis T, Janssen SJ et al. An epidemic of the use, misuse and overdose of opioids and deaths due to overdose, in the United States and Canada: is Europe next? Bone Joint J 2017; 99-B: 856-64. [PubMed][CrossRef]

3. Okie S. A flood of opioids, a rising tide of deaths. N Engl J Med 2010;363: 1981-5. [PubMed][CrossRef]

4. Håndbok i lindrende behandling. Tromsø: Universitetssykehuset Nord-Norge, 2012.

https://unn.no/Documents/Kompetansetjenester,\%20-

sentre\%20og\%2ofagr\%C3\%A5d/Regionalt\%2okompetansesenter\%2ofor\%2olindrende\%2obehandling/H \% $3 \%$ A5ndbok\%2oi\%2olindrende\%2obehandling/H\%C3\%A5ndbok\%2oi\%2olindrende\%2obehandling.pd f Lest 15.12.2019.

5. Lenz H, Sandvik L, Qvigstad E et al. A comparison of intravenous oxycodone and intravenous morphine in patient-controlled postoperative analgesia after laparoscopic hysterectomy. Anesth Analg 2009; 109:1279-83. [PubMed][CrossRef]

6. Vissers KC, Besse K, Hans G et al. Opioid rotation in the management of chronic pain: where is the evidence? Pain Pract 2010; 10: 85-93. [PubMed][CrossRef]

7. Skurtveit S, Sakshaug S, Hjellvik V et al. Bruk av vanedannende legemidler. Oslo: Folkehelseinstituttet, 2014. https://www.fhi.no/globalassets/dokumenterfiler/rapporter/2014/bruk-avvanedannende-legemidler-pdf.pdf Lest 15.12.2019.

8. Muller AE, Clausen T, Sjøgren P et al. Prescribed opioid analgesic use developments in three Nordic countries, 2006-2017. Scand J Pain 2019; 19:345-53. [PubMed][CrossRef]

9. Olkkola KT, Kontinen VK, Saari TI et al. Does the pharmacology of oxycodone justify its increasing use as an analgesic? Trends Pharmacol Sci 2013; 34: 206-14. [PubMed][CrossRef]

10. Ræder J, Dahl V, Markestad A et al. Fra ketobemidon til morfin eller oksykodon. Tidsskr Nor Legeforen 2016; 136:1518-9. [PubMed][CrossRef]

11. Dale O, Klepstad P, Tveita T et al. Re: Fra ketobemidon til morfin eller oksykodon. Tidsskr Nor Legeforen 2016; 136: 1957. [PubMed][CrossRef]

12. Riley J, Eisenberg E, Müller-Schwefe G et al. Oxycodone: a review of its use in the management of pain. Curr Med Res Opin 2008; 24: 175-92. [PubMed][CrossRef]

13. Tveito K. Opioider, makt og misbruk. Tidsskr Nor Legeforen 2019; 139. doi:10.4045/tidsskr.19.0140. [PubMed][CrossRef]

Publisert:3. september 2020. Tidsskr Nor Legeforen. DOI: 10.4045/tidsskr.20.0161

Mottatt 24.2.2020, første revisjon innsendt 22.4.2020, godkjent 7.5.2020.

Publisert under åpen tilgang CC BY-ND. Lastet ned fra tidsskriftet.no 26. april 2023. 
